\title{
"Measuring the commercial potential of new product ideas using fuzzy set theory"
}

\begin{tabular}{|c|c|}
\hline AUTHORS & $\begin{array}{l}\text { Maksym W. Sitnicki (D) } \\
\text { R } \\
\text { Valeriy Balan (D) } \\
\text { Inna Tymchenko (D) } \\
\text { Viktoriia Sviatnenko (D) } \\
\text { Anastasiia Sychova (D) }\end{array}$ \\
\hline ARTICLE INFO & $\begin{array}{l}\text { Maksym W. Sitnicki, Valeriy Balan, Inna Tymchenko, Viktoriia Sviatnenko and } \\
\text { Anastasiia Sychova (2021). Measuring the commercial potential of new product } \\
\text { ideas using fuzzy set theory. Innovative Marketing, 17(2), 149-163. } \\
\text { doi:10.21511/im.17(2).2021.14 }\end{array}$ \\
\hline DOI & http://dx.doi.org/10.21511/im.17(2).2021.14 \\
\hline RELEASED ON & Thursday, 17 June 2021 \\
\hline RECEIVED ON & Wednesday, 07 April 2021 \\
\hline ACCEPTED ON & Thursday, 10 June 2021 \\
\hline LICENSE & $\begin{array}{l}(\mathrm{cc}) \mathbf{E Y} \\
\text { This work is licensed under a Creative Commons Attribution } 4.0 \text { International } \\
\text { License }\end{array}$ \\
\hline JOURNAL & "Innovative Marketing " \\
\hline ISSN PRINT & $1814-2427$ \\
\hline ISSN ONLINE & $1816-6326$ \\
\hline PUBLISHER & LLC "Consulting Publishing Company "Business Perspectives" \\
\hline FOUNDER & LLC "Consulting Publishing Company "Business Perspectives" \\
\hline
\end{tabular}

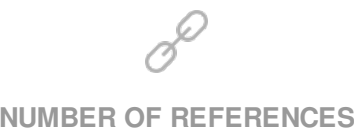

30
NUMBER OF FIGURES

4
NUMBER OF TABLES

4

(C) The author(s) 2021. This publication is an open access article. 


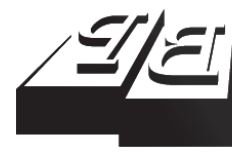

\section{BUSINESS PERSPECTIVES}

()

LLC "CPC "Business Perspectives"

Hryhorii Skovoroda lane, 10, Sumy, 40022, Ukraine

www.businessperspectives.org

Received on: $7^{\text {th }}$ of April, 2021

Accepted on: $10^{\text {th }}$ of June, 2021

Published on: 17 th of June, 2021

( $)$ Maksym W. Sitnicki, Valeriy Balan, Inna Tymchenko, Viktoriia Sviatnenko, Anastasiia Sychova, 2021.

Maksym W. Sitnicki, Dr. Sc.

(Economics), Associate Professor, Head of the Management of Innovation and Investment activities Department, Taras Shevchenko National University of Kyiv, Ukraine. (Corresponding author)

Valeriy Balan, Ph.D. (Physical and Mathematical Sciences), Associate Professor of the Management of Innovation and Investment activities Department, Taras Shevchenko National University of Kyiv, Ukraine.

Inna Tymchenko, Ph.D. (Economics) Assistant of the Management of Innovation and Investment activities Department, Taras Shevchenko National University of Kyiv, Ukraine.

Viktoriia Sviatnenko, Ph.D.

(Economics), Associate Professor of the Management of Innovation and Investment activities Department, Taras Shevchenko National University of Kyiv, Ukraine.

Anastasiia Sychova, Ph.D. student of the Management of Innovation and Investment activities Department, Taras Shevchenko National University of Kyiv, Ukraine.
Maksym W. Sitnicki (Ukraine), Valeriy Balan (Ukraine), Inna Tymchenko (Ukraine), Viktoriia Sviatnenko (Ukraine), Anastasiia Sychova (Ukraine)

\section{MEASURING THE COMMERCIAL POTENTIAL OF NEW PRODUCT IDEAS USING FUZZY SET THEORY}

\begin{abstract}
The stage of selecting creative ideas that have the prospect of further commercial use and can be used to create new products, services, or startups is one of the most complex and important stages of the innovation process. It is essential to take into account expert opinions and evaluations, often vague and ambiguous. The study aims to develop a methodological approach to measure the commercial potential of new product ideas based on fuzzy set theory and fuzzy logic. To this end, three calculation schemes are developed: the first two are based on fuzzy multicriteria analysis using Fuzzy SAW and Fuzzy TOPSIS methods, respectively; the third is based on building a logical-linguistic model with fuzzy expert knowledge bases and applying fuzzy inference using the Mamdani algorithm. Fuzzy numbers in triangular form with triangular membership functions are used to present linguistic estimates of experts and fuzzy data; the CoA (Center of Area) method is used to dephase the obtained values. For practical application of the proposed algorithm, the model is used as an Excel framework containing a general set of input expert information in the form of linguistic estimates and fuzzy data, a set of calculations using three schemes, and a set of defuzzification of the obtained results. The framework allows for simulation modeling depending on the modification of the list of defined evaluation criteria and their partial criteria, and adjustments to expert opinions. The developed methodological approach is suggested for the initial stages of the innovation process to facilitate the assessment of creative ideas and improve their implementation.
\end{abstract}

\section{Keywords logical-linguistic model, fuzzy multicriteria analysis, linguistic variables, term set}

JEL Classification $\quad$ M31, O32, C51

\section{INTRODUCTION}

Innovation is an extremely important component in achieving a competitive advantage. According to Drucker and Maciariello (2008), the organization must adhere to three principles in its work: continuous product improvement, knowledge use for its development, and systematic innovation. The need for continuous effort in innovations is also emphasized by Porter and Millar (1985), who claimed that a company achieves competitive advantage through innovation by using both new technologies and new working methods. Once a company achieves competitive advantage through innovation, the retention of this advantage is possible only through continuous improvement because competitors will overtake the company once it ceases to innovate.

One of the most responsible and critical stages in innovation is the cognitive stage, associated with the evaluation and selection of creative ideas that may become the basis for new products, goods, and services in the future. Difficulties that arise at this stage stem from its phenomenological characteristics. They include the informal nature of evalu- 
ation procedures, the vagueness of expert assessments, the need for multicriteria analysis, the presence of numerous endogenous and exogenous factors, uncertainty and risks due to increasing turbulence of business environment (Stevanović et al., 2016; Miloud et al., 2012; Messerle et al., 2012; Westerski et al., 2011; Forde \& Fox, 2016). Other equally important issues of this process include cognitive barriers that arise due to linguistic differences, systemic individual preferences of experts, as well as differences in their professional experience (Stevanović et al., 2015; Stevanović et al., 2016; Soukhoroukova et al., 2010).

Thus, the plethora of complex theoretical, methodological, and practical hindrances in the process of measuring the commercial potential of new product ideas require solutions for problems related to finding effective tools that would take into account all the specifics features of innovation management, and in particular, facilitate the analysis and selection of promising creative ideas.

\section{THEORETICAL BASIS}

Innovation is the driving force of the economy and the key to the successful development of a business. Barsh et al. (2007) revealed that more than $70 \%$ of executives believe that innovation is a top strategic priority for their companies. A creative idea is the starting point of any innovation. There are several types of ideas:

- an old idea - an idea of the 'past experience' (i.e. an idea that has already been used to create new products, new knowledge, new ideas, etc.);

- a new idea, which is a development or improvement of an old idea;

- an integrated new idea based on:

a) several old ideas or approaches from one field of knowledge or field of application;

b) a few old ideas or approaches from different fields of knowledge or areas of application.

In particular, Sutton (2013) while researching innovative activities of companies such as Play-Doh and Apple iPod, normally focused only on the integrated new ideas. It was argued that "innovation and creativity is first and foremost the ability to create something new based on old things and ideas, not the ability to create something new out of nothing".

- $\quad$ and, a 'completely new (revolutionary), unique idea' that had no analogs, not even close ones in the past; and such an idea has the potential to become a driver that may uncover a whole layer of previously unresolved issues and suggest new technologies and methods for solving them.

Stevanović et al. (2016) discovered that most companies prioritize developing new product ideas, but only in response to consumer requests, as this study was constrained by limited investment resources and issues related to human resources. Accordingly, the role of proper selection that saves effort and resources is growing as, according to recent studies, the failure is to be expected in at least $95 \%$ of the total number of new products in the US market and $90 \%$ of those in European markets. Thus, measuring the potential of creative ideas is a critical stage in innovation management as mistakes and errors at this stage may later lead to serious losses and strategic failures.

In this study, the ideas of Siegel et al. (1995), Jain et al. (2003), as well as the commercial potential of creative ideas are considered as an integral indicator of the promise.

An important aspect of measuring the commercial potential of a new product idea comprises a range of questions related to finding optimal evaluation procedures and their methodological support, including the development of evaluation criteria. For example, Messerle et al. (2012) developed a model for selecting and evaluating ideas that consists of eight stages: idea generation, idea capture, initial evaluation and selection, initial idea detailing, rough evaluation and selection, second idea detailing, detailed valuation, and selection, and implementation of the product idea. Westerski et al. (2011) suggested five stages of idea selection management: idea generation, idea im- 
provement, idea selection, idea implementation, and idea deployment. These stages are meant to ensure the integrity of cyclicity of the computer-assisted idea management process. At the initial stages of the idea generation process, this methodology provides for interaction between the stakeholders and the telecommunications infrastructure. Miloud et al. (2012) conducted an empirical study of idea evaluation in terms of ideas attractiveness for investment and developed several groups of evaluation factors: industry attractiveness, the organizational and entrepreneurial experience of the founder and the team, which are important for obtaining positive evaluation results. A systemic approach was used to identify factors and their selection for new product idea evaluation. Riel et al. (2013) developed a benchmark model for the ideation process based on fuzzy interface and expert evaluations. Based on that six critical success factors for ideas were singled out: ideation starts at the top management, ideation needs a clearly defined focus, ideation happens in networks, ideation demands creativity, ideation needs entrepreneurship, and ideation requires organizational orientation. It was suggested to select ideas using managerial decision-making frameworks, or "a set of tools for ideation". Trolle et al. (2020) studied the problems of using fuzzy evaluations at the stage of new product idea implementation and singled out the following evaluation factors: project, team, organization, and external environment impact factors. Gors et al. (2012) suggested sorting out innovative product ideas by combining individual and team-based methods of managerial decision-making and setting several requirements, such as speed, acceptance, computer support, minimizing cognitive load, and minimizing selection errors. The algorithm is based on FEoI decision-making method, single-criteria, and multi-criteria methods. Travessini et al. (2015) used the AHP support method for making decisions in the process of selecting new product ideas. Forde and Fox (2016) described the idea evaluation process based on the development of requirements for such a process and used the notion of utility to measure the probability of an idea being executed.

The most effective tools for evaluating new ideas are approaches that take into account the subjective and qualitative (linguistic) nature of expert evaluations, their vagueness, and fuzziness. In particular, Soukhoroukova et al. (2010) suggested using fuzzy methods to study the effectiveness of idea markets in three stages: selection, filtering, and evaluation. It is crucial to create a platform where it will be possible not only to place ideas but also to share experiences and express opinions. Huynh and Nakamori (2011) suggested the use of linguistic estimates to select ideas but identified a key drawback of the approach, namely the loss of information through approximation. At the same time, a model was proposed in which calculations are performed on the basis of the semantics of linguistic terms and the two-tune transformation, which is necessary for the unification of linguistic information. Malyar et al. (2016) developed a two-level model for evaluating startups (creative ideas) in conditions of uncertainty using fuzzy mathematics, which involves the use of experts' linguistic estimates of various membership functions, which may lead to certain ambiguity of the outcomes.

The variety of ideas and the complexity of the process of measuring their commercial potential call for the search of flexible and adaptive tools for comparative analysis and the development of effective algorithms and procedures to better take into account subjective, informal, fuzzy inputs, experts' opinions, and assumptions. Accordingly, this study uses fuzzy economic and mathematical modeling techniques to assess the commercial potential of creative ideas for a new product. The foundations of the fuzzy logic theory, based on the mathematical theory of fuzzy sets, were proposed by Zadeh (1965) and Zadeh (1978). Kosko (1993) made a very important step in the development of 'fuzzy' methodology, where any mathematical system can be approximated by a system built on fuzzy logic. This gave a powerful impetus to continue studies in this area, and practical advances in fuzzy logic were theoretically substantiated. The fuzzy set theory approach has three main features:

1) instead of or in addition to numerical variables, fuzzy quantities and so-called 'linguistic' variables are used;

2) simple relations between variables are described by vague statements;

3) complex relations are described by fuzzy algorithms. 
This study uses the fuzzy set theory tools, including fuzzy multicriteria analysis methods (Fuzzy SAW-method (FSAW), Fuzzy TOPSIS-method (FTOPSIS) (Chen, 2000), and systems of fuzzy inference (Mamdani, 1977) to solve the set tasks of assessing the level of the commercial potential of creative ideas of a new product. The process of fuzzy inference is an algorithm for obtaining fuzzy inferences based on fuzzy conditions using the concepts of fuzzy logic. This process combines all the basic concepts of fuzzy set theory: belonging functions, logical, linguistic operations, methods of fuzzy implication, and fuzzy composition.

The need to consider a large number of factors influencing the level of risk and uncertainty of the outcome, the multidimensionality of the process, the presence of complex indirect links between evaluation criteria, vagueness and ambiguity of expert assessments call for the search for unconventional tools for formalizing cognitive processes to analyze parameters and content of creative ideas.

\section{AIMS}

This study aims to develop a methodological approach to measuring the commercial potential of creative product ideas and their selection using multi-criteria analysis, fuzzy set theory, and fuzzy logic.

\section{RESULTS}

To measure the level of the commercial potential of new ideas for a new product, a methodological

Stage 1. Setting up a group of experts.

Stage 2. Making a list of promising creative ideas.

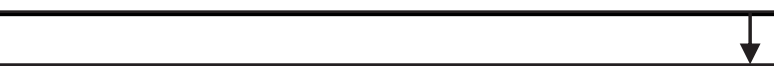

Stage 3. Establishing a system of evaluation criteria for commercial potential of creative ideas and breaking them down into sub-criteria.

Stage 4. Defining weights of criteria and sub-criteria for evaluating commercial potential of creative ideas.

Stage 5. Expert evaluation of commercial potential of creative ideas according to defined sub-criteria and building relevant fussy 'decision matrices'.

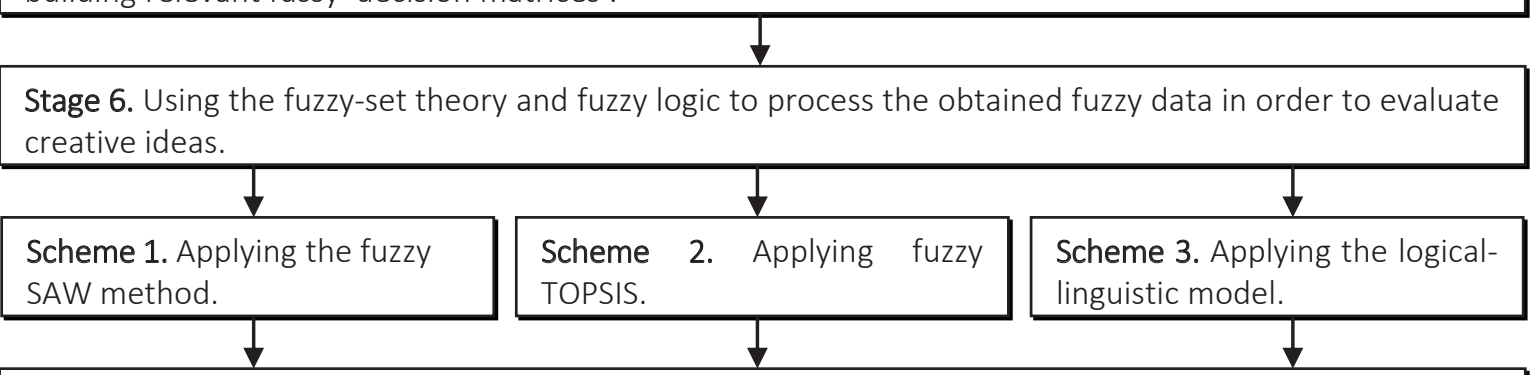

Stage 7. Checking the consistency of obtained results and building a generalized range of creative ideas according to their commercial potential.

Stage 8. Applying the obtained data for taking relevant managerial decisions.

Figure 1. Measuring the commercial potential of creative ideas 
approach was developed. Figure 1 demonstrates the main stages of this approach.

The stages of the suggested methodological approach aimed at measuring the commercial potential of creative ideas are as follows.

Stage 1. Setting up a working group of experts with relevant professional competencies and responsibilities. According to Soukhoroukova et al. (2010), "the inclusion of multiple, various evaluators appears beneficial for the idea selection process. Within a company, these evaluators may represent different organizational functions, such as marketing, research and development (R\&D), and production". It is advised to include external experts who have qualifications and relevant competencies in the area.

Stage 2. It involves drawing up a general list of creative ideas for a new product based on various ideation procedures (using synectic methods, brainstorming, morphological analysis, etc.). According to Rometty (2006), the most important sources of ideas are employees (41\%), business partners and customers (over 35\%), consultants and competitors (over $20 \%$ each), internal sales and service departments, and internal R\&D (slightly less than 20\%).

Stage 3. This stage is one of the most complex and important, as it should provide a foundation for comparative analysis of creative ideas. Modern methodological tools for solving the problem of analysis and selection of creative ideas are characterized by a variety of approaches to defining evaluation criteria. Empirical research has helped to identify certain sets of criteria. For example, Polishchuk et al. (2016) suggested five groups of criteria: the essence of the idea, the authors of the idea, the comparative characteristics of the idea, the commercial significance of the idea, and the expected results. Jain et al. (2003) singled out six groups of criteria: economic, market, technical, technological, human, and unique aspects. Bandarian (2007), based on Jain et al. (2003), suggested a list containing an evaluation of the process, perception of the end-user, technical, economic, market, and legal evaluations. Soukhoroukova et al. (2010) used four groups of criteria: attractiveness in the ideas market, qual- ity of search and filtering, and overall efficiency. Wierik (2019) identified three groups of criteria: individual, pertaining to the external environment, and related to process and organization. Stevanović et al. (2015) suggested using technical, market, financial, social, and consumer factors to evaluate ideas.

Based on the results of a broad and detailed analysis of existing literature and empirical studies, the generalization method was used and the following list of criteria for evaluating ideas was suggested, which is quite general and may be adjusted depending on the industry and specific tasks:

- creative: originality; unexpectedness; attractiveness; provocativeness; relevance; effectiveness; novelty; elegance; genesis; pleasingness;

- technical and technological: reliability; compatibility/trialability; relative advantage; acceptability; development of enabling technologies; aesthetics; R\&D intensity; functionality; safety; environmental friendliness; prototype; gracefulness; cost of development and production cost; after-sales service;

- financial: ROI; stock index; sales volume; perceived risk; stakeholder support; the magnitude of the percentage growth of the market for this idea; the amount of expected income in 5 years; cost amortization period;

- market: market size; advertising intensity; competition; usability; exiting market stimulation/satisfaction; market acceptance; intellectual property; potential market share;

- organizational: team; incentives/disincentives/regulations; managerial capacity; ability to evaluate risk; management leadership abilities; social significance; affordability.

Stage 4. To determine the importance of the criteria and their evaluation sub-criteria, the following steps must be performed.

Step 1. Linguistic evaluation by each of the $K$ experts of the importance of evaluation criteria, and their sub-criteria. To do this, one can use a seven-level term set (Table 1). 


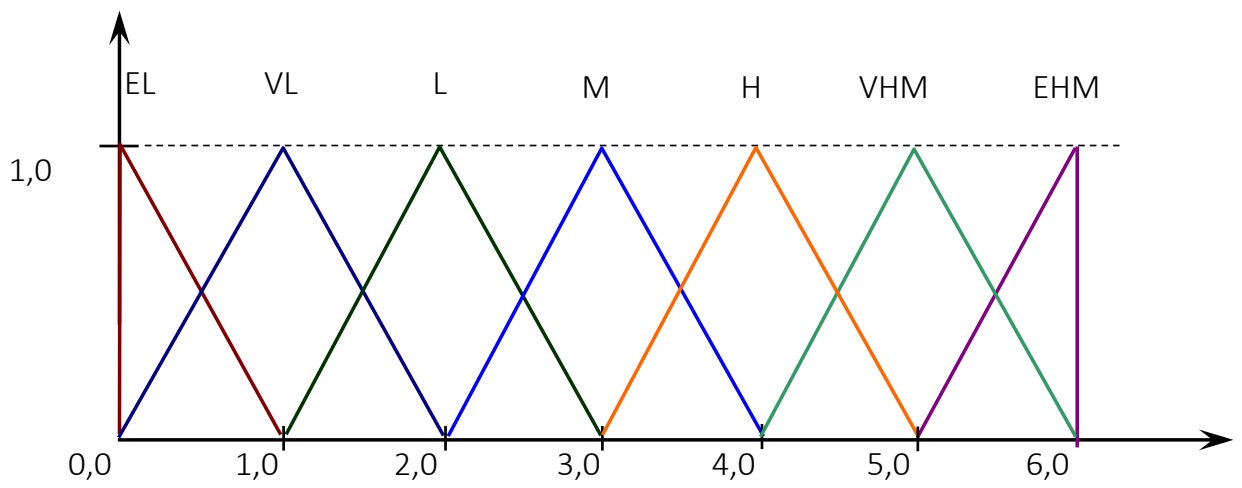

Figure 2. Evaluation terms of membership functions

Table 1. Term set with respective triangular fuzzy numbers

\begin{tabular}{l|c|c}
\hline \multicolumn{1}{c|}{ Linguistic term } & Designation & $\begin{array}{c}\text { Triangular fuzzy } \\
\text { number }\end{array}$ \\
\hline Extremely Low & $\mathrm{EL}$ & $(0 ; 0 ; 1)$ \\
\hline Very Low & $\mathrm{VL}$ & $(0 ; 1 ; 2)$ \\
\hline Low & $\mathrm{L}$ & $(1 ; 2 ; 3)$ \\
\hline Medium & $\mathrm{M}$ & $(2 ; 3 ; 4)$ \\
\hline High & $\mathrm{H}$ & $(3 ; 4 ; 5)$ \\
\hline Very High & $\mathrm{VH}$ & $(4 ; 5 ; 6)$ \\
\hline Extremely High & $\mathrm{EH}$ & $(5 ; 6 ; 6)$ \\
\hline
\end{tabular}

For example, analytical representation of the membership function for a term with a triangular representation $\tilde{u}=(a ; b ; c)$ will look as follows:

$$
\mu(x)=\left\{\begin{array}{l}
0, x<a \\
(x-a) /(b-a), x \in[a ; b] \\
(c-x) /(c-b), x \in[b ; c] ; \\
0, x>c .
\end{array}\right.
$$

For defuzzification of a fuzzy number $(a ; b ; c)$, one can use formula (2) of the CoA (Center of Area) method (Van Leekwijck \& Kerre, 1999):

$$
\operatorname{def}(\tilde{u})=\frac{(c-a)+(b-a)}{3}+a .
$$

Thus, linguistic evaluation leads to the following important valuations:

1) evaluation criteria: $L_{k}^{C}, L_{k}^{T}, L_{k}^{F}, L_{k}^{M}, L_{k}^{O}$, $k=1,2, \ldots, K$

2. evaluation sub-criteria: $l_{j k}^{C}$

$$
\begin{aligned}
& \left(j=1,2, \ldots, n^{C}\right), l_{j k}^{T}\left(j=1,2, \ldots, n^{T}\right), \\
& l_{j k}^{F}\left(j=1,2, \ldots, n^{F}\right), l_{j k}^{M}
\end{aligned}
$$

$$
\begin{aligned}
& \left(j=1,2, \ldots, n^{M}\right), l_{j k}^{O}\left(j=1,2, \ldots, n^{O}\right), \\
& k=1,2, \ldots, K .
\end{aligned}
$$

Step 2. Transformation of experts' linguistic evaluations, obtained in step 1, into fuzzy triangular numbers:

$$
\begin{aligned}
& L_{k}^{C} \rightarrow \tilde{V}_{k}^{C}=\left(X_{k}^{C} ; Y_{k}^{C} ; Z_{k}^{C}\right), \\
& L_{k}^{T} \rightarrow \tilde{V}_{k}^{T}=\left(X_{k}^{T} ; Y_{k}^{T} ; Z_{k}^{T}\right), \\
& L_{k}^{F} \rightarrow \tilde{V}_{k}^{F}=\left(X_{k}^{F} ; Y_{k}^{F} ; Z_{k}^{F}\right), \\
& L_{k}^{M} \rightarrow \tilde{V}_{k}^{M}=\left(X_{k}^{M} ; Y_{k}^{M} ; Z_{k}^{M}\right), \\
& L_{k}^{O} \rightarrow \tilde{V}_{k}^{O}=\left(X_{k}^{O} ; Y_{k}^{O} ; Z_{k}^{O}\right) ; \\
& l_{j k}^{C} \rightarrow \tilde{v}_{j k}^{C}=\left(\alpha_{j k}^{C} ; \beta_{j k}^{C} ; \gamma_{j k}^{C}\right), \\
& l_{j k}^{T} \rightarrow \tilde{v}_{j k}^{T}=\left(\alpha_{j k}^{T} ; \beta_{j k}^{T} ; \gamma_{j k}^{T}\right), \\
& l_{j k}^{F} \rightarrow \tilde{v}_{j k}^{F}=\left(\alpha_{j k}^{F} ; \beta_{j k}^{F} ; \gamma_{j k}^{F}\right), \\
& l_{j k}^{M} \rightarrow \tilde{v}_{j k}^{M}=\left(\alpha_{j k}^{M} ; \beta_{j k}^{M} ; \gamma_{j k}^{M}\right), \\
& l_{j k}^{O} \rightarrow \tilde{v}_{j k}^{O}=\left(\alpha_{j k}^{O} ; \beta_{j k}^{O} ; \gamma_{j k}^{O}\right) .
\end{aligned}
$$

Step 3. Aggregation of experts' fuzzy evaluations according to formulae (3) - (7) and (8) - (12):

$$
\begin{aligned}
& \tilde{V}^{C}=\left(\bigoplus_{k=1}^{K} \tilde{V}_{k}^{C}\right) / K= \\
& =\left(\left(\sum_{k=1}^{K} X_{k}^{C}\right) / K ;\left(\sum_{k=1}^{K} Y_{k}^{C}\right) / K ;\left(\sum_{k=1}^{K} Z_{k}^{C}\right) / K\right)= \\
& =\left(X^{C} ; Y^{C} ; Z^{C}\right)
\end{aligned}
$$




$$
\begin{aligned}
& \tilde{V}^{T}=\left(\bigoplus_{k=1}^{K} \tilde{V}_{k}^{T}\right) / K= \\
& =\left(\left(\sum_{k=1}^{K} X_{k}^{T}\right) / K ;\left(\sum_{k=1}^{K} Y_{k}^{T}\right) / K ;\left(\sum_{k=1}^{K} Z_{k}^{T}\right) / K\right)= \\
& =\left(X^{T} ; Y^{T} ; Z^{T}\right) \\
& \tilde{V}^{F}=\left(\bigoplus_{k=1}^{K} \tilde{V}_{k}^{F}\right) / K= \\
& =\left(\left(\sum_{k=1}^{K} X_{k}^{F}\right) / K ;\left(\sum_{k=1}^{K} Y_{k}^{F}\right) / K ;\left(\sum_{k=1}^{K} Z_{k}^{F}\right) / K\right)= \\
& =\left(X^{F} ; Y^{F} ; Z^{F}\right) \\
& \tilde{V}^{M}=\left(\bigoplus_{k=1}^{K} \tilde{V}_{k}^{M}\right) / K= \\
& =\left(\left(\sum_{k=1}^{K} X_{k}^{M}\right) / K ;\left(\sum_{k=1}^{K} Y_{k}^{M}\right) / K ;\left(\sum_{k=1}^{K} Z_{k}^{M}\right) / K\right)= \\
& =\left(X^{M} ; Y^{M} ; Z^{M}\right) \\
& \tilde{V}^{O}=\left(\bigoplus_{k=1}^{K} \tilde{V}_{k}^{O}\right) / K= \\
& =\left(\left(\sum_{k=1}^{K} X_{k}^{O}\right) / K ;\left(\sum_{k=1}^{K} Y_{k}^{O}\right) / K ;\left(\sum_{k=1}^{K} Z_{k}^{O}\right) / K\right)= \\
& =\left(X^{O} ; Y^{O} ; Z^{O}\right) \\
& \tilde{v}_{j}^{C}=\left(\bigoplus_{k=1}^{K} \tilde{v}_{j k}^{C}\right) / K=\left(\alpha_{j}^{C} ; \beta_{j}^{C} ; \gamma_{j}^{C}\right), \\
& j=1,2, \ldots, n^{C} \text {, } \\
& \tilde{v}_{j}^{T}=\left(\bigoplus_{k=1}^{K} \tilde{v}_{j k}^{T}\right) / K=\left(\alpha_{j}^{T} ; \beta_{j}^{T} ; \gamma_{j}^{T}\right), \\
& j=1,2, \ldots, n^{T} \text {, } \\
& \tilde{v}_{j}^{F}=\left(\bigoplus_{k=1}^{K} \tilde{v}_{j k}^{F}\right) / K=\left(\alpha_{j}^{F} ; \beta_{j}^{F} ; \gamma_{j}^{F}\right), \\
& j=1,2, \ldots, n^{F} \text {, } \\
& \tilde{v}_{j}^{M}=\left(\bigoplus_{k=1}^{K} \tilde{v}_{j k}^{M}\right) / K=\left(\alpha_{j}^{M} ; \beta_{j}^{M} ; \gamma_{j}^{M}\right) \text {, } \\
& j=1,2, \ldots, n^{M} \text {, } \\
& \tilde{v}_{j}^{O}=\left(\bigoplus_{k=1}^{K} \tilde{v}_{j k}^{O}\right) / K=\left(\alpha_{j}^{O} ; \beta_{j}^{O} ; \gamma_{j}^{O}\right) \text {, } \\
& j=1,2, \ldots, n^{O} \text {. }
\end{aligned}
$$

Step 4. Defuzzification of the obtained wights according to the formula (2). As a result, the following 'crisp' values are obtained:

1) for evaluation criteria: $\operatorname{def}\left(\tilde{V}^{C}\right), \operatorname{def}\left(\tilde{V}^{T}\right)$, $\operatorname{def}\left(\tilde{V}^{F}\right), \operatorname{def}\left(\tilde{V}^{M}\right), \operatorname{def}\left(\tilde{V}^{O}\right) ;$

2) for their sub-criteria: $\operatorname{def}\left(\tilde{v}_{j}^{C}\right), \operatorname{def}\left(\tilde{v}_{j}^{T}\right)$, $\operatorname{def}\left(\tilde{v}_{j}^{F}\right), \operatorname{def}\left(\tilde{v}_{j}^{M}\right), \operatorname{def}\left(\tilde{v}_{j}^{O}\right)$.

Step 5. The normalization of weights:

1) for evaluation criteria: $W^{C}=\operatorname{def}\left(\tilde{V}^{C}\right) / S V$;

$$
\begin{aligned}
& W^{T}=\operatorname{def}\left(\tilde{V}^{T}\right) / S V ; \\
& W^{F}=\operatorname{def}\left(\tilde{V}^{F}\right) / S V ; \\
& W^{M}=\operatorname{def}\left(\tilde{V}^{M}\right) / S V ; \\
& W^{O}=\operatorname{def}\left(\tilde{V}^{O}\right) / S V, \text { where } \\
& S V=\operatorname{def}\left(\tilde{V}^{C}\right)+\operatorname{def}\left(\tilde{V}^{T}\right)+ \\
& +\operatorname{def}\left(\tilde{V}^{F}\right)+\operatorname{def}\left(\tilde{V}^{M}\right)+\operatorname{def}\left(\tilde{V}^{O}\right) .
\end{aligned}
$$

1) for their sub-criteria: $w_{j}^{C}=\frac{\operatorname{def}\left(\tilde{v}_{j}^{C}\right)}{\sum_{t=1}^{n^{C}} \operatorname{def}\left(\tilde{v}_{t}^{C}\right)}$

$$
\begin{aligned}
& w_{j}^{T}=\frac{\operatorname{def}\left(\tilde{v}_{j}^{T}\right)}{\sum_{t=1}^{n^{T}} \operatorname{def}\left(\tilde{v}_{t}^{T}\right)} ; \quad w_{j}^{F}=\frac{\operatorname{def}\left(\tilde{v}_{j}^{F}\right)}{\sum_{t=1}^{n^{F}} \operatorname{def}\left(\tilde{v}_{t}^{F}\right)} ; \\
& w_{j}^{M}=\frac{\operatorname{def}\left(\tilde{v}_{j}^{M}\right)}{\sum_{t=1}^{n^{M}} \operatorname{def}\left(\tilde{v}_{t}^{M}\right)} ; \quad w_{j}^{O}=\frac{\operatorname{def}\left(\tilde{v}_{j}^{O}\right)}{\sum_{t=1}^{n^{O}} \operatorname{def}\left(\tilde{v}_{t}^{O}\right)} .
\end{aligned}
$$

Stage 5. To measure the commercial potential of creative ideas according to the sub-criteria defined at the previous stage, each of these sub-criteria is considered as a linguistic variable, for which one can use the same term set as for evaluating criteria, followed by transformation of obtained values into triangular fuzzy numbers. If, according to some subcriteria, the measurement is based on fuzzy data in the form of intervals $\left[a_{i j k} ; c_{i j k}\right]$, they can be triangulated as follows: $\left[a_{-j j k} ; c_{i j k}\right] \rightarrow\left(a_{i j k} ; b_{i j k} ; c_{i j k}\right)$, where $b_{i j k} \in\left[a_{i j k} ; c_{i j k}\right]$ determines the value for which the degree of affiliation is equal to 1 . 
Further, it is necessary to normalize the obtained fuzzy data using the following relations:

$$
\left(\frac{a_{i j k}}{\max _{r} c_{r j k}} ; \frac{b_{i j k}}{\max _{r} c_{r j k}} ; \frac{c_{i j k}}{\max c_{r j k}}\right)
$$

- for criteria with a monotonically increasing objective function (benefit criteria) and

$$
\left(\frac{\min _{r} a_{r j k}}{c_{i j k}} ; \frac{\min _{r} a_{r j k}}{b_{i j k}} ; \frac{\min _{r} a_{r j k}}{a_{i j k}}\right)
$$

- for criteria with a monotonically decreasing objective function (cost criteria).

Suppose that as a result of this procedure, the fuzzy normalized triangular estimate of the $i$-creative idea $(i=1,2, \ldots, N) k$-expert $(k=1,2, \ldots, K)$ according to $j$-sub-criteria of the relevant evaluation criteria looks as follows: $\tilde{C}_{i j k}=\left(x_{i j k}^{C} ; y_{i j k}^{C} ; z_{i j k}^{C}\right)$

- for criterion $\mathrm{C}\left(j=1,2, \ldots, n^{C}\right)$,

$\tilde{T}_{i j k}=\left(x_{i j k}^{T} ; y_{i j k}^{T} ; z_{i j k}^{T}\right)$

- for criterion $\mathrm{T}\left(j=1,2, \ldots, n^{T}\right)$,

$\tilde{F}_{i j k}=\left(x_{i j k}^{F} ; y_{i j k}^{F} ; z_{i j k}^{F}\right)$

- for criterion $F\left(j=1,2, \ldots, n^{F}\right)$,

$\tilde{M}_{i j k}=\left(x_{i j k}^{M} ; y_{i j k}^{M} ; z_{i j k}^{M}\right)$

- for criterion $M\left(j=1,2, \ldots, n^{M}\right)$,

$\tilde{O}_{i j k}=\left(x_{i j k}^{O} ; y_{i j k}^{O} ; z_{i j k}^{O}\right)$

- for criterion $O\left(\left(j=1,2, \ldots, n^{O}\right)\right.$.

To aggregate the fuzzy values obtained from all experts, one should use formulae (13) - (17):

$\tilde{C}_{i j}=\bigoplus_{k=1}^{K} \tilde{C}_{i j k}=$

$=\left(\sum_{k} x_{i j k}^{C} / K ; \sum_{k} y_{i j k}^{C} / K ; \sum_{k} z_{i j k}^{C} / K\right)=$

$=\left(x_{i j}^{C} ; y_{i j}^{C} ; z_{i j}^{C}\right)$;

$$
\tilde{T}_{i j}=\bigoplus_{k=1}^{K} \tilde{T}_{i j k}=
$$

$=\left(\sum_{k} x_{i j k}^{T} / K ; \sum_{k} y_{i j k}^{T} / K ; \sum_{k} z_{i j k}^{T} / K\right)=$
$\tilde{F}_{i j}=\bigoplus_{k=1}^{K} \tilde{F}_{i j k}=$

$=\left(\sum_{k} x_{i j k}^{F} / K ; \sum_{k} y_{i j k}^{F} / K ; \sum_{k} z_{i j k}^{F} / K\right)=$

$=\left(x_{i j}^{F} ; y_{i j}^{F} ; z_{i j}^{F}\right)$;

$\tilde{M}_{i j}=\bigoplus_{k=1}^{K} \tilde{M}_{i j k}=$

$=\left(\sum_{k} x_{i j k}^{M} / K ; \sum_{k} y_{i j k}^{M} / K ; \sum_{k} z_{i j k}^{M} / K\right)=$

$=\left(x_{i j}^{M} ; y_{i j}^{M} ; z_{i j}^{M}\right)$;

$\tilde{O}_{i j}=\bigoplus_{k=1}^{K} \tilde{O}_{i j k}=$

$=\left(\sum_{k} x_{i j k}^{O} / K ; \sum_{k} y_{i j k}^{O} / K ; \sum_{k} z_{i j k}^{O} / K\right)=$

$=\left(x_{i j}^{O} ; y_{i j}^{O} ; z_{i j}^{O}\right)$.

Scheme 1 based on the Fuzzy SAW method involves performing the following steps:

1) to apply the FSAW-method, one can use the relations (18) - (22). The result will be fuzzy values of the level of the commercial potential of creative ideas $(i=1,2, \ldots, N)$ according to certain criteria:

$$
\begin{aligned}
& \tilde{C}_{i}=\bigoplus_{j=1}^{n^{C}} w_{j}^{C} \tilde{C}_{i j}= \\
& =\left(\sum_{j=1}^{n^{C}} w_{j}^{C} x_{i j}^{C} ; \sum_{j=1}^{n^{C}} w_{j}^{C} y_{i j}^{C} ; \sum_{j=1}^{n^{C}} w_{j}^{C} z_{i j}^{C}\right)= \\
& =\left(x_{i}^{C} ; y_{i}^{C} ; z_{i}^{C}\right) ; \\
& \tilde{T}_{i}=\bigoplus_{j=1}^{n^{T}} w_{j}^{T} \tilde{T}_{i j}= \\
& =\left(\sum_{j=1}^{n^{T}} w_{j}^{T} x_{i j}^{T} ; \sum_{j=1}^{n^{T}} w_{j}^{T} y_{i j}^{T} ; \sum_{j=1}^{n^{T}} w_{j}^{T} z_{i j}^{T}\right)= \\
& =\left(x_{i}^{T} ; y_{i}^{T} ; z_{i}^{T}\right) ;
\end{aligned}
$$




$$
\begin{aligned}
& \tilde{F}_{i}=\bigoplus_{j=1}^{n^{F}} w_{j}^{F} \tilde{F}_{i j}= \\
& =\left(\sum_{j=1}^{n^{F}} w_{j}^{F} x_{i j}^{F} ; \sum_{j=1}^{n^{F}} w_{j}^{F} y_{i j}^{F} ; \sum_{j=1}^{n^{F}} w_{j}^{F} z_{i j}^{F}\right)= \\
& =\left(x_{i}^{F} ; y_{i}^{F} ; z_{i}^{F}\right) ; \\
& \tilde{M}_{i}=\bigoplus_{j=1}^{n^{M}} w_{j}^{M} \tilde{M}_{i j}= \\
& =\left(\sum_{j=1}^{n^{M}} w_{j}^{M} x_{i j}^{M} ; \sum_{j=1}^{n^{M}} w_{j}^{M} y_{i j}^{M} ; \sum_{j=1}^{n^{M}} w_{j}^{M} z_{i j}^{M}\right)= \\
& =\left(x_{i}^{M} ; y_{i}^{M} ; z_{i}^{M}\right) ; \\
& \tilde{O}_{i}=\bigoplus_{j=1}^{n^{O}} w_{j}^{O} \tilde{O}_{i j}= \\
& =\left(\sum_{j=1}^{n^{O}} w_{j}^{O} x_{i j}^{O} ; \sum_{j=1}^{n^{O}} w_{j}^{O} y_{i j}^{O} ; \sum_{j=1}^{n^{O}} w_{j}^{O} z_{i j}^{O}\right)= \\
& =\left(x_{i}^{O} ; y_{i}^{O} ; z_{i}^{O}\right) .
\end{aligned}
$$

2) to determine the integrated level of commercial potential of the $i$ - idea, on can also use the FSAW-method by formula (23):

$\tilde{P}_{i}=W^{C} \tilde{C}_{i} \oplus W^{T} \tilde{T}_{i} \oplus W^{F} \tilde{F}_{i} \oplus W^{M} \tilde{M}_{i} \oplus W^{O} \tilde{O}_{i}=$ $=\left(W^{C} x_{i}^{C} ; W^{C} y_{i}^{C} ; W^{C} z_{i}^{C}\right) \oplus$

$\oplus\left(W^{T} x_{i}^{T} ; W^{T} y_{i}^{T} ; W^{T} z_{i}^{T}\right) \oplus$

$\left(W^{F} x_{i}^{F} ; W^{F} y_{i}^{F} ; W^{F} z_{i}^{F}\right) \oplus$

$\left(W^{M} x_{i}^{M} ; W^{M} y_{i}^{M} ; W^{M} z_{i}^{M}\right) \oplus$
$\oplus\left(W^{o} x_{i}^{o} ; W^{o} y_{i}^{o} ; W^{o} z_{i}^{o}\right)=\left(P_{i}^{x} ; P_{i}^{y} ; P_{i}^{z}\right)$,

$(i=1,2, \ldots, N)$.

3) using the defuzzification procedure by formula (2) for $\tilde{C}_{i}, \tilde{T}_{i}, \tilde{F}_{i}, \tilde{M}_{i}, \tilde{O}_{i}$ and $\tilde{P}_{i}$, one can calculate the crisp-value of the commercial potential of each analyzed idea according to certain criteria and its (commercial potential) integral value, respectively.

Scheme 2 involves using the fuzzy TOPSIS method (Chen, 2000).

Suppose that $N_{1}=n^{C}, \quad N_{2}=n^{C}+n^{T}$, $N_{3}=n^{C}+n^{T}+n^{F}, \quad N_{4}=n^{C}+n^{T^{T}}+n^{F}+n^{M}$, $L=n^{C}+n^{T}+n^{F}+n^{M}+n^{O}$.

Next, one determines the weights of the sub-criteria, taking into account the importance of the main criteria, and labels them as follows (Table 2).

It is also necessary to re-label the aggregate fuzzy estimates obtained according to formulae (18) (22) by subcriteria (Table 3).

Thus, fuzzy matrix obtained is $\tilde{R}=\left\|\tilde{r}_{i j}\right\|_{N \times L}$, where $\tilde{r}_{i j}=\left(r_{i j}^{x} ; r_{i j}^{y} ; r_{i j}^{z}\right)$.

The next step is to weigh the normalized matrix: $\tilde{R} \rightarrow \tilde{P}$, where $\tilde{P}=\left\|\tilde{p}_{i j}\right\|_{N \times L}$ and $\tilde{p}_{i j}=w_{j} \times \tilde{r}_{\tilde{\tilde{p}}}$,

\begin{tabular}{|c|c|c|c|c|}
\hline $\begin{array}{c}\text { For criterion } \\
\text { C }\end{array}$ & $\begin{array}{c}\text { For criterion } \\
\mathrm{T} \\
\end{array}$ & $\begin{array}{c}\text { For criterion } \\
F\end{array}$ & $\begin{array}{c}\text { For criterion } \\
M\end{array}$ & $\begin{array}{c}\text { For criterion } \\
0 \\
\end{array}$ \\
\hline$w_{1}=W^{C} w_{1}^{C}$ & $w_{N_{1}+1}=W^{T} w_{1}^{T}$ & $w_{N_{2}+1}=W^{F} w_{1}^{F}$ & $w_{N_{3}+1}=W^{M} w_{1}^{M}$ & $w_{N_{4}+1}=W^{O} w_{1}^{O}$ \\
\hline$w_{2}=W^{C} w_{2}^{C}$ & $w_{N_{1}+2}=W^{T} w_{2}^{T}$ & $w_{N_{2}+2}=W^{F} w_{2}^{F}$ & $w_{N_{3}+2}=W^{M} w_{2}^{M}$ & $w_{N_{4}+2}=W^{O} w_{2}^{O}$ \\
\hline & $\cdots$ & & & $\cdots$ \\
\hline$w_{N_{1}}=W^{C} w_{n^{C}}^{C}$ & $w_{N_{2}}=W^{T} w_{n^{T}}^{T}$ & $w_{N_{3}}=W^{F} w_{n^{T}}^{F}$ & $w_{N_{4}}=W^{M} w_{n^{M}}^{M}$ & $w_{L}=W^{O} w_{n^{o}}^{O}$ \\
\hline
\end{tabular}
$i=1,2, \ldots, N, \quad j=1,2, \ldots \times, L . \quad$ Suppose $\tilde{p}_{i j}$ is represented as: $\tilde{p}_{i j}=\left(p_{i j}^{x} ; p_{i j}^{y} ; p_{i j}^{z}\right)$. Then, $\varphi_{j}^{+}=\max _{\tilde{A}^{i}} p_{i j}^{z}$ and $\varphi_{j}^{-}=\min _{i} p_{i j}^{x}$ and next we obtain $\tilde{A}^{+i}$ (FPIS fuzzy ideal ${ }^{i}$ positive solution) and $\tilde{A}^{-}$(FNIS - fuzzy negative ideal solution):

$\tilde{A}^{+}=\left(\tilde{p}_{1}^{+} ; \tilde{p}_{2}^{+} ; \ldots ; \tilde{p}_{L}^{+}\right)$, where

Table 2. Evaluation sub-crietria weights for fuzzy TOPSIS

Source: Authors' elaboration. 
Table 3. Fuzzy matrix of "solutions" for the application of fuzzy TOPSIS

Source: Authors' elaboration.

\begin{tabular}{|c|c|c|c|c|}
\hline $\begin{array}{c}\text { For criterion } \\
\text { C } \\
\end{array}$ & $\begin{array}{c}\text { For criterion } \\
\mathrm{T} \\
\end{array}$ & $\begin{array}{c}\text { For criterion } \\
F \\
\end{array}$ & $\begin{array}{c}\text { For criterion } \\
M \\
\end{array}$ & $\begin{array}{c}\text { For criterion } \\
0 \\
\end{array}$ \\
\hline$\tilde{C}_{i 1} \rightarrow \tilde{r}_{i 1}$ & $\tilde{T}_{i 1} \rightarrow \tilde{r}_{i\left(N_{1}+1\right)}$ & $\tilde{F}_{i 1} \rightarrow \tilde{r}_{i\left(N_{2}+1\right)}$ & $\tilde{M}_{i 1} \rightarrow \tilde{r}_{i\left(N_{3}+1\right)}$ & $\tilde{O}_{i 1} \rightarrow \tilde{r}_{i\left(N_{4}+1\right)}$ \\
\hline$\tilde{C}_{i 2} \rightarrow \tilde{r}_{i 2}$ & $\tilde{T}_{i 2} \rightarrow \tilde{r}_{i\left(N_{1}+2\right)}$ & $\tilde{F}_{i 2} \rightarrow \tilde{r}_{i\left(N_{2}+2\right)}$ & $\tilde{M}_{i 2} \rightarrow \tilde{r}_{i\left(N_{3}+2\right)}$ & $\tilde{O}_{i 2} \rightarrow \tilde{r}_{i\left(N_{4}+2\right)}$ \\
\hline$\ldots$ & $\ldots$ & $\ldots$ & $\ldots$ & $\ldots$ \\
\hline$\tilde{C}_{i n^{C}} \rightarrow \tilde{r}_{i N_{1}}$ & $\tilde{T}_{i n^{T}} \rightarrow \tilde{r}_{i N_{2}}$ & $\tilde{F}_{i n^{F}} \rightarrow \tilde{r}_{i N_{3}}$ & $\tilde{M}_{i n^{M}} \rightarrow \tilde{r}_{i N_{4}}$ & $\tilde{O}_{i n}{ }^{o} \rightarrow \tilde{r}_{i L}$ \\
\hline
\end{tabular}

$\tilde{p}_{j}^{+}=\left(\varphi_{j}^{+} ; \varphi_{j}^{+} ; \varphi_{j}^{+}\right) ; \tilde{A}^{-}=\left(\tilde{p}_{1}^{-} ; \tilde{p}_{2}^{-} ; \ldots ; \tilde{p}_{L}^{-}\right)$, where $\tilde{p}_{j}^{-}=\left(\varphi_{j}^{-} ; \varphi_{j}^{-} ; \varphi_{j}^{-}\right)$.

Next, it is necessary to calculate "distances" between each set alternative and the:

a) fuzzy perfect positive solution:

$$
\begin{aligned}
& d\left(\tilde{A}_{i} ; \tilde{A}^{+}\right)=\sum_{j=1}^{L} d\left(\tilde{p}_{i j} ; p_{j}^{+}\right)= \\
& =\sum_{j=1}^{L} \sqrt{\frac{1}{3}\left(\left(p_{i j}^{x}-\varphi_{j}^{+}\right)^{2}+\left(p_{i j}^{y}-\varphi_{j}^{+}\right)^{2}+\left(p_{i j}^{z}-\varphi_{j}^{+}\right)^{2}\right)} ;
\end{aligned}
$$

b) fuzzy perfect negative solution:

$$
\begin{aligned}
& d\left(\tilde{A}_{i} ; \tilde{A}^{-}\right)=\sum_{j=1}^{L} d\left(\tilde{p}_{i j} ; \tilde{p}_{j}^{-}\right)= \\
& =\sum_{j=1}^{L} \sqrt{\frac{1}{3}\left(\left(p_{i j}^{x}-\varphi_{j}^{-}\right)^{2}+\left(p_{i j}^{y}-\varphi_{j}^{-}\right)^{2}+\left(p_{i j}^{z}-\varphi_{j}^{-}\right)^{2}\right) .}
\end{aligned}
$$

As a result of applying these relations, crisp estimates are obtained, which can be used to rank creative ideas by calculating the relative distance from each of the given alternatives to FPIS and FNIS according to the formula:

$$
C C_{i}=\frac{d\left(\tilde{A}_{i} ; \tilde{A}^{-}\right)}{d\left(\tilde{A}_{i} ; \tilde{A}^{-}\right)+d\left(\tilde{A}_{i} ; \tilde{A}^{+}\right)} .
$$

Scheme 3 is based on the Mamdani fuzzy inference system algorithm (Mamdani, 1977) and can be used to account for fuzzy expert estimates without using fuzzy additive weighing procedures as in the FSAW method and finding the distance to ideal positive and negative alternatives as in the
FTOPSIS method. In this case, fuzzy inference is performed on FKBs (Fuzzy Knowledge Bases), which are developed on the basis of professional expert judgment. This scheme can be implemented according to the following algorithm (Figure 3).

Step 1. Here, if there are accurate expert evaluations and interval data of creative ideas according to certain sub-criteria, then they should be transformed into linguistic estimates. Then fuzzification of all linguistic estimates is carried out, i.e. their translation into triangular fuzzy numbers with the corresponding triangular membership functions.

Step 2. Development of fuzzy knowledge bases based on the production rules of fuzzy logic, which allow summarizing and integrating information about each creative idea according to certain sub-criteria of each evaluation criterion. The weights of the sub-criteria need to be considered when constructing fuzzy rule databases, as this affects the combinations of terms of the input variables in the conjunction.

Table 4 shows a section of the fuzzy knowledge base FKB (C) to determine the level of the commercial potential of ideas according to the sub-criteria of criterion C - 'creativity'.

A fuzzy knowledge base, for example, to determine the overall level of the commercial potential of a creative idea by the criterion of 'creativity' in mathematical form is written using the production rules of fuzzy logic as follows:

$\bigvee_{r=1}^{L_{j}}\left({ }_{i=1}^{n^{C}} C_{i}=d_{j i}^{C}\right.$ with $\left.q_{j r}^{C}\right) \rightarrow y^{C}=d_{j}^{C}$ 
Source: Authors' elaboration.

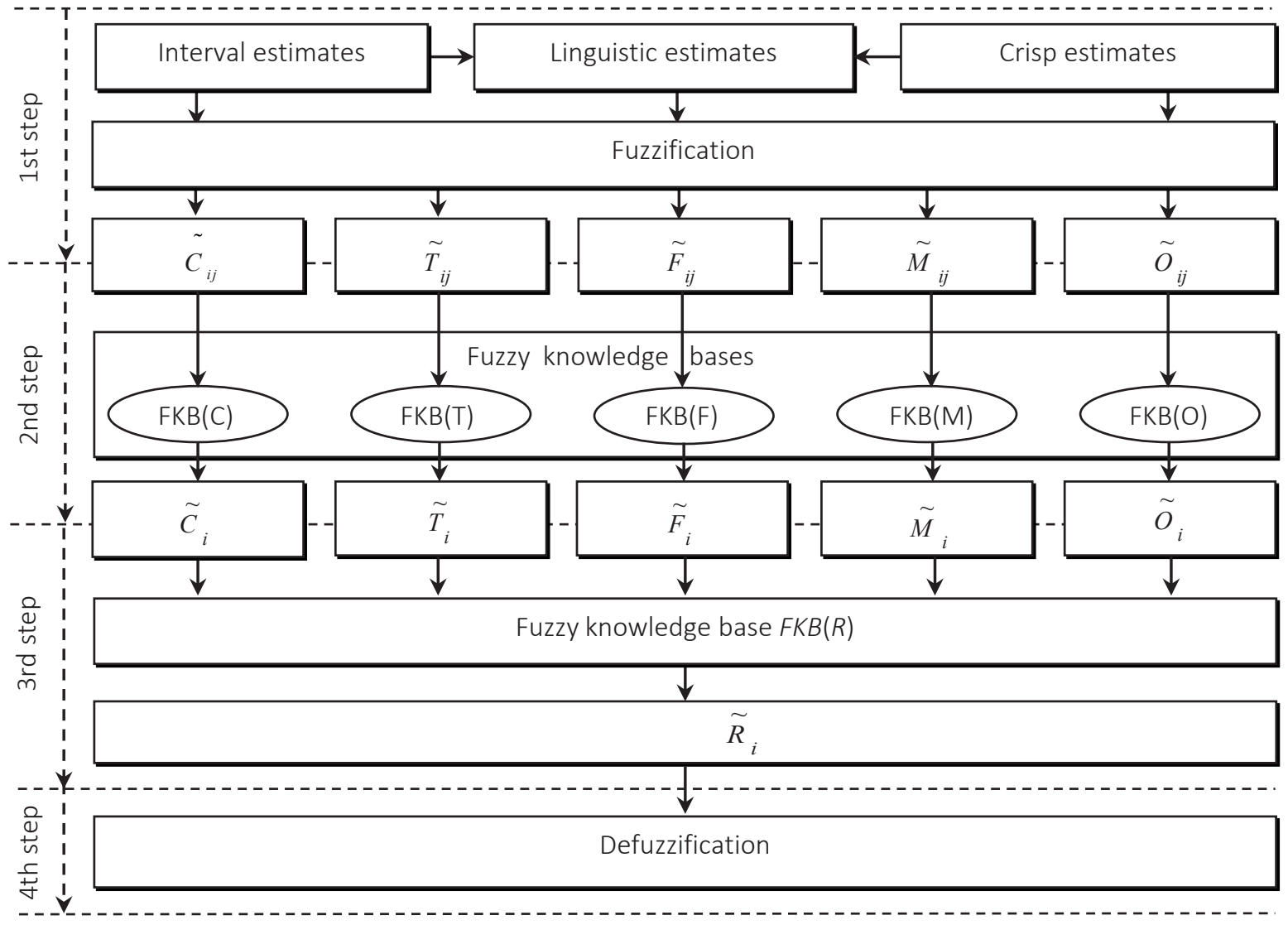

Figure 3. The system structure of Mamdani fuzzy inference

Table 4. Section of the FKB (C) - fuzzy knowledge base to determine the level of ideas' commercial potential according to the sub-criteria of criterion C - 'creativity'

Source: Authors' elaboration.

\begin{tabular}{|c|c|c|c|c|c|c|c|}
\hline \multirow{3}{*}{$\begin{array}{c}\text { No of rule } \\
r_{11}\end{array}$} & \multicolumn{4}{|c|}{ Linguistic values of original variables } & \multirow[b]{2}{*}{ Weights } & \multirow{2}{*}{\multicolumn{2}{|c|}{ Original variable value $d$}} \\
\hline & $C_{1}$ & $C_{2}$ & $\ldots$ & $C_{n^{c}}$ & & & \\
\hline & EL & EL & $\ldots$ & EL & $q_{11}^{C}$ & \multirow{4}{*}{$d_{1}^{C}$} & \multirow{4}{*}{ EL } \\
\hline$r_{12}$ & $V L$ & EL & $\cdots$ & EL & $q_{12}^{C}$ & & \\
\hline$\ldots . .$. & $\ldots$ & $\ldots .$. & $\ldots$ & $\ldots$ & $\ldots \ldots$ & & \\
\hline$r_{1 L_{1}}$ & EL & EL & $\ldots$ & $V L$ & $q_{1 L_{1}}^{C}$ & & \\
\hline$r_{21}$ & $V L$ & $\mathrm{VL}$ & $\ldots$ & $\mathrm{VL}$ & $q_{21}^{C}$ & \multirow{4}{*}{$d_{2}^{C}$} & \multirow{4}{*}{$V L$} \\
\hline$r_{22}$ & EL & VL & ... & VL & $q_{22}^{C}$ & & \\
\hline$\ldots \ldots$ & $\ldots$ & $\ldots .$. & $\cdots$ & $\ldots$ & $\ldots \ldots$ & & \\
\hline$r_{2 L_{2}}$ & $\mathrm{VL}$ & $\mathrm{VL}$ & $\ldots$ & L & $q_{2 L_{12}}^{C}$ & & \\
\hline$\ldots . .$. & $\ldots \ldots$ & $\ldots$ & $\cdots$ & $\ldots$. & $=$ & $\ldots$ & $\ldots$ \\
\hline$r_{71}$ & EH & $\mathrm{H}$ & $\ldots$ & $\mathrm{EH}$ & $q_{71}^{C}$ & \multirow{4}{*}{$d_{7}^{C}$} & \multirow{4}{*}{$\mathrm{EH}$} \\
\hline$r_{72}$ & H & $\mathrm{EH}$ & $\cdots$ & EH & $q_{72}^{C}$ & & \\
\hline$\ldots \ldots \ldots$ & $\ldots$ & $\ldots$ & & $\ldots . .$. & $\ldots$ & & \\
\hline$r_{7 L_{7}}$ & $\mathrm{EH}$ & $\mathrm{EH}$ & $\ldots$ & $\mathrm{EH}$ & $q_{7 L_{7}}^{C}$ & & \\
\hline
\end{tabular}


Accordingly, the decisive rule will be written as follows:

$$
\begin{aligned}
& \mu^{d_{j}^{R}}\left(C_{1}, C_{2}, \ldots, C_{n^{c}}\right)=\left(q_{j 1}^{C} \bigwedge_{s=1}^{n^{C}} \mu_{s}^{j 1}\left(C_{s}\right)\right) \vee \\
& \vee\left(q_{j 2}^{C} \bigwedge_{s=1}^{n^{c}} \mu_{s}^{j 2}\left(C_{s}\right)\right) \vee \cdots \vee\left(q_{j L_{j}}^{C} \bigwedge_{s=1}^{n^{c}} \mu_{s}^{j L_{j}}\left(C_{s}\right)\right)= \\
& =\underset{r=1}{L_{j}}\left(q_{j r}^{C}{ }_{s=1}^{n^{c}} \mu_{s}^{j r}\left(C_{s}\right)\right)
\end{aligned}
$$

where $\wedge$ - the sign of fuzzy conjunction, $\vee$ - the sign of fuzzy disjunction, $\mu^{d_{j}^{c}}\left(C_{1}, C_{2}, \ldots, C_{n^{c}}\right)$ the function of the vector of input variables belonging to the value of the output variable $d_{j}^{C} ; L_{j}$ - the number of combinations of values of variables $C_{1}, C_{2}, \ldots, C_{c^{c}}$, where the original variable takes value $d_{j}^{C} ; q_{j p}^{C^{n}}$ - weighting of the $p$-combination $\left(p=\overline{1, L_{j}}\right)$ for the original variable $d_{j}^{C}$; $\mu_{s}^{j p}\left(C_{s}\right)$ - the membership function of the original variable $C_{s}$ to the fuzzy term $d_{s}^{j p}\left(s=1, n^{C}\right)$.

Similar databases of fuzzy knowledge need to be built for other criteria used for evaluating creative ideas.

Step 3. Aggregation of fuzzy estimates according to the criteria obtained in the previous step into an integrated measurement of the commercial potential is performed for each analyzed idea. To do this, as in the previous step, one needs to build a fuzzy knowledge base $F K B(C)$.
Step 4. It involves defuzzification according to formula (2) of the obtained fuzzy values of the commercial potential of the analyzed ideas according to individual criteria and their integrated level.

Stage 7. To check the consistency of the results obtained by different schemes, one can calculate, for example, the concordance coefficient. After that, a generalized ranking of creative ideas according to their commercial potential must be built.

Stage 8. The obtained ranking data for creative ideas can be used to develop appropriate managerial decisions, in particular, to stratify ideas or identify the most promising one(s) for further implementation.

To facilitate the practical application of the developed methodological approach, the model is developed as an Excel framework, containing the following main blocks: $B_{1}$ - input of expert information as linguistic estimates and fuzzy data ( $B_{11}$ - for evaluating criteria, $B_{12}$ - sub-criteria, and $B_{13}$ - creative ideas), $B_{2}$ - calculations according to three schemes ( $B_{21}$ - FSAW, $B_{22}$ - FTOPSIS, $B_{23}$ - Mamdani fuzzy inference system), $B_{3}$ - defuzzification of the obtained results (Figure 4).

The framework allows one to perform simulation modeling depending on:

c) modification of the list of defined evaluation criteria and their sub-criteria;

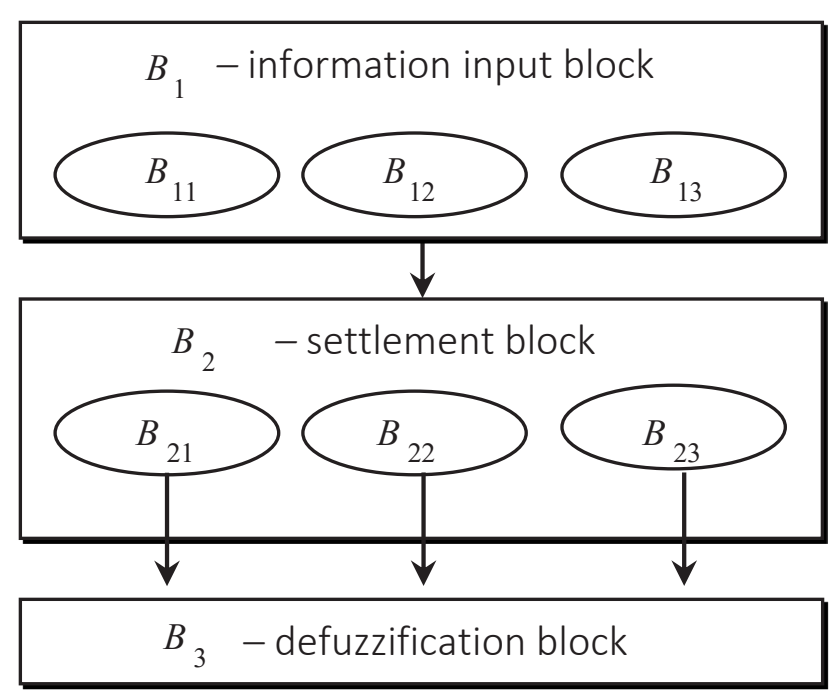

Source: Authors' elaboration.

Figure 4. Main blocks of the framework of the developed methodological approach 
d) linguistic estimates of the importance of criteria and their sub-criteria;

e) expert evaluations of creative ideas according to certain sub-criteria.

\section{DISCUSSION}

Although the developed methodology has several advantages over existing approaches, the complexity of the research problem may require further discussion of the following aspects:

1) building the original set of creative ideas from a general list for their evaluation according to certain criteria;

2) organizational and methodological aspects of determining criteria and singling out sub-criteria for evaluating creative ideas;

3) solving the problem of compensatory effects when using the FSAW method;

4) using Excel software for the development of the framework where the possibilities and potential of logical-linguistic modeling and "soft" computations of fuzzy set theory are somewhat limited.

As follows from the above-mentioned issues, as well as any other aspects for discussion, further research on the topic of this study may aim at improving the following components of the suggested methodological approach: selecting expert group members based on the level of their competence and experience in the subject area;

- establishing and applying simple heuristic procedures of reduction for the initial set of ideas to reject unpromising or irrelevant ones; for example, using the method of criterion constraints to set minimum requirements for the criteria;

- improving the procedure for forming evaluation criteria using fuzzy tools; for example, Fuzzy DEMATEL-method;

- developing and including procedures for harmonization of experts' opinions at all stages of the evaluation process;

- developing a framework for evaluation and selecting creative ideas for a new product using specialized applications that encompass the possibilities of fuzzy modeling, for example, Fuzzy Logic Toolbox of the Matlab computer system, Fuzzy Control Design Toolbox, fuzzyTECH, etc.

A further task of an applied nature can be the approbation of this methodological approach by adapting the evaluation criteria and their sub-criteria following the needs of the analysis, taking into account various aspects of the situation.

\section{CONCLUSION}

This study aims to develop an improved solution for one of the most critical and complex tasks in innovation management, namely the problem of measuring the commercial potential of creative ideas. This problem should be considered through the prism of subjective perception of each member of the expert group as they see their promise for new goods, products, or services. The suggested methodology for the analysis and evaluation of creative ideas uses the tools of fuzzy set theory. In particular, fuzzy multicriteria methods FSAW, FTOPSIS, and logical-linguistic modeling based on Mamdani fuzzy inference algorithm are used. They provide for a more comprehensive and flexible approach to the process due to fuller consideration of various factors, as well as subjective, informal, fuzzy input data, opinions, and judgments of experts. The Excel-based framework developed for the suggested methodology helps to reduce the complexity of analytical calculations by suggested schemes, allows assessing the reliability of the results, and can be used as the basis for creating appropriate management decision support systems. The suggested methodology will be most effective when all the three calculation schemes are used together; yet, in case of limited resources, lack of time, etc., only one of the calculation schemes or a combination thereof may be applied. 


\section{AUTHOR CONTRIBUTIONS}

Conceptualization: Maksym W. Sitnicki, Valeriy Balan.

Data curation: Valeriy Balan, Maksym W. Sitnicki, Inna Tymchenko, Viktoriia Sviatnenko, Anastasiia Sychova.

Formal analysis: Maksym W. Sitnicki, Valeriy Balan, Inna Tymchenko, Viktoriia Sviatnenko, Anastasiia Sychova.

Investigation: Maksym W. Sitnicki, Valeriy Balan.

Methodology: Valeriy Balan, Maksym W. Sitnicki, Inna Tymchenko, Viktoriia Sviatnenko, Anastasiia Sychova.

Project administration: Maksym W. Sitnicki.

Resources: Inna Tymchenko, Viktoriia Sviatnenko, Valeriy Balan, Anastasiia Sychova, Maksym W. Sitnicki.

Validation: Valeriy Balan, Maksym W. Sitnicki, Inna Tymchenko, Viktoriia Sviatnenko, Anastasiia Sychova.

Visualization: Valeriy Balan, Maksym W. Sitnicki.

Writing - original draft: Maksym W. Sitnicki, Valeriy Balan, Inna Tymchenko, Viktoriia Sviatnenko, Anastasiia Sychova.

Writing - review \& editing: Maksym W. Sitnicki, Valeriy Balan.

\section{ACKNOWLEDGMENT}

This scientific paper is published with the support of the International Visegrad Fund.

\section{REFERENCES}

1. Astebro, T. (2004). Key Success Factors for Technological Entrepreneurs' R\&D Projects. IEEE Transactions on Engineering Management, 51(3), 314-321. 10.1109/ TEM.2004.830863

2. Bandarian, R. (2007). Measuring Commercial Potential of a New Technology at the Early Stage of Development with Fuzzy Logic. Journal of Technology Management \& Innovation, 2(4), 73-85.

Retrieved from https://www.jotmi. org/index.php/GT/article/view/ art65/429

3. Barsh, J., Capozzi, M. \& Mendonca, L. (2007). How companies approach innovation: A McKinsey Global Survey. McKinsey Quarterly. Retrieved from https://www.elkarbide.com/sites/ default/files/MCKINSEY\%20 INNOVACI\%C3\%93N.pdf

4. Chen, C. T. (2000). Extensions of the TOPSIS for group decisionmaking under fuzzy environment. Fuzzy Sets and Systems, 114, 1-9. https://doi.org/10.1016/S0165-

\section{4(97)00377-1}

5. Drucker, P. F., \& Maciariello, J. A. (2008). Management (Revised ed.). New York: Harper Collins.

6. Forde, A. N., \& Fox, M. S. (2016). A Proposed Approach for Idea Selection in Front End of Innovation Activities. Technology Innovation Management Review, 6(8), 48-55. http://doi.org/10.22215/timreview/1011

7. Gors, J. Horton, G., \& Kempe, N. (2012). A Collaborative Algorithm for Computer-Supported Idea Selection in the Front End of Innovation. $45^{\text {th }}$ Hawaii International Conference on System Sciences, 217-226. http://doi.org/10.1109/ HICSS.2012.48

8. Herrmann, T., Laukemann, A., Binz, H., \& Rot, D. (2018). The Emoji Method: An Approach for Identifying and Formulating Problem Ideas. International Scholarly and Scientific Research \& Innovation, 12(12), 1071-1086. Retrieved from https://zenodo.org/
record/2363264\#.YMUXiPkzaUk

9. Huynh, V., \& Nakamori, Y. (2011). A Linguistic Screening Evaluation Model in New Product Development. IEEE Transactions on Engineering Management, 58(1), 165-175. http://doi.org/10.1109/ TEM.2009.2028326.

10. Jain, R. K., Martyniuk, A. O., Harris, M. M., Niemann, R. E., \& Woldmann, K. (2003). Evaluating the commercial potential of emerging technologie. International Journal of Technology Transfer and Commercialisation, 2(1), 32-50. https://doi.org/10.1504/ IJTTC.2003.001800

11. Kosko, B. (1993). Fuzzy Thinking: The New Science of Fuzzy Logic. Hyperion.

12. Malyar, N., Polishchuk, V., Sharkad, M., \& Liakh, I. (2016). Model of startups assessment under conditions of information uncertainty. EasternEuropean Journal of Enterprise Technologies, 3(4(81), 43-49. 
https://doi.org/10.15587/17294061.2016.71222

13. Mamdani, E. H. (1977). Application of Fuzzy Logic to Approximate ReasoningUsing Linguistic Synthesis. IEEE Transactions on Computers, 26(12), 11821191. https://doi.org/10.1109/ TC.1977.1674779

14. Messerle, M., Binz, H., \& Roth, D. (2012). Existing problems of idea evaluations and possible areas of improvement. Proceedings of the $12^{\text {th }}$ International Design Conference - Design 2021, 1917-1928. Dubrovnik, Croatia. Retrieved from https://www.semanticscholar. org/paper/EXISTING-PROBLEMS-OF-IDEA-EVALUATIONSAND-POSSIBLE-Messerle-Binz/ c78417bb74d6174863cd465e11bebae023b6b87f

15. Miloud, T., Aspelund, A., \& Cabrol, M. (2012). Startup valuation by venture capitalists: an empirical study. Venture Capital, 14(2-3), 151-174. https://doi.org/10.1080/1 3691066.2012.667907

16. Porter, M., \& Millar, V. (1985). How Information Gives You Competitive Advantage. Harvard Business Review, 63(4), 149-160. Retrieved from https://palfreymanventures.net/porter-andmillar-1985.pdf

17. Riel, A., Neumann, M., \& Tichkiewitch, S. (2013). Structuring the early fuzzy front-end to manage ideation for new product development. CIRP Annals Manufacturing Technology, 62(1), 107-110. https://doi.org/10.1016/J. CIRP.2013.03.128

18. Rometty, G. (2006). Expanding the Innovation Horizon: The Global CEO Study 2006. IBM Global Business Services. Retrieved from http://www.businessmodelinnovation.org.sg/wp-content/uploads/2015/01/global_ceo_study. pdf

19. Siegel, R. A., Hansén, S. O., \& Pellas, L. H. (1995). Accelerating the commercialization of technology: commercialization through co-operation. Industrial Management \& Data Systems, 95(1), 18-26. https://doi. org/10.1108/02635579510079425
20. Soukhoroukova, A., Spann, M., \& Skiera, B. (2010). Sourcing, Filtering, and Evaluating New Product Ideas: An Empirical Exploration of the Performance of Idea Markets. Journal of Product Innovation Management, 29(1), 100-112. https://doi.org/10.1111/j.15405885.2011.00881.x

21. Stevanović, M., Marjanović, D., \& Štorga, M. (2015). A Model of Idea Evaluation and Selection for Product Innovation. Proceedings from $20^{\text {th }}$ International Conference on Engineering Design (ICED 15), 8: Innovation and Creativity, 27-30. Italy. Retrieved from https://www.researchgate.net/ publication/283425054_A_Model_of_Idea_Evaluation_and_Selection_for_Product_Innovation

22. Stevanović, M., Marjanović, D., \& Štorga, M. (2016). Idea management in product innovationthe empirical research results. Tehnički vjesnik: znanstvenostručni časopis tehničkih fakulteta Sveučilišta u Osijeku, 23(5), 12851294. https://doi.org/10.17559/ TV-20150603223629

23. Sutton, R. (2013). Okhota za ideyami: Kak otorvatsia ot konkurentov, narushaya vse pravila [Hunt for ideas. How to have a head start on competitors by breaking all the rules]. Moscow: Alpina Publisher. (In Russian).

24. Travessini, R., Rodrigues, T., Braghini, J., Colmenero, J. C., Beinlich, S., \& Zocche, L. (2015). Selection of ideas in the furniture industry with the help of the method Analytic Hierarchy Process (AHP). Espacios, 36(9), 2-12. Retrieved from https:// www.researchgate.net/publication/281738434_Selection_of_ ideas_in_the_furniture_industry_ with_the_help_of_the_method_ Analytic_Hierarchy_Process_AHP

25. Trolle, J., Fagerström, B., \& Rosio, C. (2020). Challenges in the Fuzzy Front End of the Production Development Process. Advances in Transdisciplinary Engineering, 13, 311-322. https://doi.org/10.3233/ ATDE200169

26. Van Leekwijck, W., \& Kerre, E. E. (1999). Defuzzification: criteria and classification. Fuzzy Sets and Systems, 108(2), 159-178. https://doi.org/10.1016/S01650114(97)00337-0

27. Westerski, A., Iglesias, C. A., \& Nagle, T. (2011). The road from community ideas to organisational innovation: a life cycle survey of idea management systems. International Journal of Web Based Communities, 7(4), 493-506. https://doi.org/10.1504/ IJWBC.2011.042993

28. Wierik, T. M. (2019). Analyzing investment decision criteria for blockchain startups (Bachelor Thesis). University of Twente. Retrieved from http://purl.utwente. $\mathrm{nl} /$ essays/78563

29. Zadeh, L. A. (1978). Fuzzy Sets as a Basis for a Theory of Possibility. Fuzzy Sets and Systems, 1(1), 89100. https://doi.org/10.1016/0165 0114(78)90029-5

30. Zadeh, L. A. (1965). Fuzzy Sets. Information and Control, 8, 338353. https://doi.org/10.1016/ S0019-9958(65)90241-X 